\title{
Positive psychology outcome measures for family caregivers of people living with
}

\section{dementia: A systematic review}

Jacki Stansfeld ${ }^{1,2}$, Charlotte R. Stoner ${ }^{3}$, Jennifer Wenbornn ${ }^{1,2}$, Myrra Vernooij-Dassen ${ }^{4}$, Esme Moniz-Cook ${ }^{5}$ and Martin Orrell

\footnotetext{
${ }^{1}$ Division of Psychiatry, University College London, Maple House, 149 Tottenham Court Road, London, UK

2 Research and Development, North East London NHS Foundation Trust, Goodmayes Hospital, IG38XJ, UK

${ }^{3}$ Department of Clinical, Educational and Health Psychology, University College London, 1-19 Torrington Place, London, UK.

${ }^{4}$ Radboud University Medical Centre, Postbus 9101, 6500 HB Nijmegen, The Netherlands

${ }^{5}$ Faculty of Health and Social Care, University of Hull, UK

${ }^{6}$ Institute of Mental Health, University of Nottingham, Triumph Road, Nottingham, UK
}

Corresponding Author: Jacki Stansfeld, Division of Psychiatry, University College London, Maple House, 149 Tottenham Court Road, London, W1T 7NF

Email: Jacki.Stansfeld@nelft.nhs.uk

Telephone: 03005551200 ext 64491 / 07834392294 


\begin{abstract}
Background: Family caregivers of people living with dementia can have both positive and negative experiences of caregiving. Despite this, existing outcome measures predominately focus on negative aspects of caregiving such as burden and depression. This review aimed to evaluate the development and psychometric properties of existing positive psychology measures for family caregivers of people living with dementia to determine their potential utility in research and practice.
\end{abstract}

Method: A systematic review of positive psychology outcome measures for family caregivers of people with dementia was conducted. The databases searched were: PsychINFO, CINAHL, MEDLINE, EMBASE and PubMed. Scale development papers were subject to a quality assessment to appraise psychometric properties.

Results: 12 positive outcome measures and 6 validation papers of these scales were identified. The emerging constructs of self-efficacy, spirituality, resilience, rewards, gain and meaning are in line with positive psychology theory.

Conclusions: There are some robust positive measures in existence for family caregivers of people living with dementia. However, lack of reporting of the psychometric properties hindered the quality assessment of some outcome measures identified in this review. Future research should aim to include positive outcome measures in interventional research to facilitate a greater understanding of the positive aspects of caregiving and how these contribute to wellbeing.

Key words: Dementia, Alzheimer's disease, carers, rating scales

Running title: Positive psychology measures for family carers 


\section{Introduction}

It is estimated that there will be 100 million people worldwide with dementia by 2050 (World Health Organization, 2012). The majority of people with dementia live in the community, with care provided by an estimated 670,000 family and friends in the UK alone (Alzheimer's Society, 2014). Previous research into family caregivers of people with dementia has often been weighted towards constructs such as burden, depression and stress (Dickinson et al., 2016; Cooper et al. 2007; Crespo et al., 2005). Positive and negative states can coexist in caregiving (Lawton et al., 1991; Tremont, 2011), yet whilst caregivers report positive aspects of caring, the role of these positive aspects in wellbeing has been largely overlooked (Roff et al., 2004; Tarlow et al 2004), and has only received attention more recently (Carbonneau et al., 2010; Orgeta and Leung, 2015). These positive aspects of caregiving can serve as a protective factor for the burden of caregiving (Koerner et al., 2009).

The positive psychology framework uses the study of strengths, virtues and positive emotions that enable people to thrive (Seligman et al., 2005) to achieve a greater understanding of wellbeing, even in the face of difficult circumstances (Keyes and Lopez, 2005; Clarke and Wolverson, 2016). The majority of research in this field has focused on the general population, but there has been recent interest in mental health (Macaskill, 2016) and in outcomes for people with dementia (Clarke and Wolverson, 2016). Despite the increasing attention to the role of positive psychology in the wellbeing of caregivers, interventional studies continue to assess caregiver's wellbeing in the framework of a lossdeficit model, often measuring wellbeing by the absence of negative factors such as stress 
and depression. The stress-coping model (Lazarus and Folkman, 1984) and subsequent adaptions (Aneshensel et al., 1995; Pearlin et al., 1990) have been criticised for the lack of inclusion of positive concepts, which aid the understanding of wellbeing and experiences of this population (Dickenson et al., 2016; Tarlow et al., 2004).

Studies exploring how families can have positive experiences despite the stress in dementia caregiving have most commonly noted the importance of self-efficacy, resilience, and sense of coherence. Aside from these popular constructs, there is historically a scarcity of relevant positive psychology outcome measures used in interventional research with this population (Tarlow et al., 2004; Wilks et al., 2011; Crellin et al., 2014). Recently, existing measures of positive psychology validated within the general population have begun to be applied within caregiver research. However, researchers often pay little attention to the psychometric implications of adopting measures developed for other populations.

\section{Aim}

The aim of this review was to identify positive psychology measures for family caregivers of people living with dementia, with good psychometric properties. It also aimed to undertake a quality assessment to establish the potential utility of identified outcome measures in research and practice and to recommend which may be most appropriate.

\section{Method}

Design

A systematic search was conducted to identify positive psychology outcome measures developed for or validated with family caregivers of people living with dementia in the 
community. Systematic principles outlined by the PRISMA group were followed for searching and screening results (Moher et al., 2009). A psychometric property appraisal of the measures identified was conducted using published quality criteria for assessing the measurement characteristics of outcome measures (Terwee et al., 2007).

\section{Search Strategy}

The following electronic databases were searched: PsychINFO, CINHAL, MEDLINE, EMBASE and PubMed. In addition to this, hand searching of references and prior citations were performed. Positive psychology search terms were derived from scoping existing literature using Seligman's definition of positive psychology, "the study of strengths, virtues and positive emotions that enable people to thrive" (Seligman et al., 2005) and the Values in Action (VIA) framework as a guide (Peterson \& Seligman, 2002). The VIA framework proposes character strengths grouped within six sets of 'virtues': transcendence, temperance, justice, humanity, courage and wisdom. An additional check for other potential search terms was performed by comparing identified terms from the literature with a related review of positive psychology measures for chronic illness, traumatic brain injury and older adults (Stoner et al., 2015).

Search terms were: measure AND positive psychology AND family caregiver AND dementia. The variants on terms used were as follows:

Search terms for measure included: 'measure' OR 'outcome' OR 'instrument' OR 'questionnaire' OR 'quiz' OR 'test' OR 'psychometric' OR 'analysis' OR 'validation' OR 'reliability' OR 'validity' OR 'scale'. Search terms for positive psychology were: 'self-efficacy' OR 'hope' OR 'gain' OR 'resilience', 'wisdom' OR 'growth' OR 'sense of coherence' OR ‘belief 
in a just world' OR 'control' OR 'autonomy', 'pleasure' OR 'self-realisation' OR 'positivity' OR 'optimism' OR 'agency' OR 'gratitude' OR 'satisfaction' OR 'outlook' OR 'uplift' OR 'meaning' OR 'happiness' OR 'transcendence' OR 'self-concept' OR 'humour' OR 'creativity' OR 'spirituality' OR 'love' OR 'compassion' OR 'mindfulness' OR 'affability'.

Search terms for family caregiver included: 'family carer' OR 'caregiver' OR 'care' OR 'relative' OR 'friend' OR 'spouse'

Search terms for dementia were: 'cognitive impairment' OR 'Alzheimer' OR 'senile' OR 'dementia' OR 'demented'.

Truncations of search terms were used where appropriate. All titles and abstracts were screened against the inclusion and exclusion criteria and specifically for the inclusion of a positive psychology measure developed for or validated with family caregivers of people living with dementia in the community. When an outcome measure was identified, a search for the relevant psychometric and/or development study was conducted.

\section{Inclusion Criteria}

- Publication language: Studies published in English only, unless a translation is available

- Publication year: Studies published between 1980 (to include the point from which positive psychology ideas, such as 'flow' emerged in the literature) and October 2015 (date of the search)

- Outcome measures developed for or validated with a population of family caregivers of people living with dementia in the community (i.e not those living in a care home) 
- Outcome measures with psychometric properties published in a peer-reviewed journal

- Outcome measures related to a positive psychology construct or positive psychology traits

\section{Exclusion Criteria}

- Outcome measures only measuring external or situational contributors to wellbeing such as social support and external locus of control. These are excluded in order to restrict the breadth of the review to internal sources of wellbeing such as positive traits, strengths and virtues detailed in the VIA framework (Peterson \& Seligman, 2002).

\section{Data Extraction}

Papers were exported to Mendeley Referencing Software, where the titles were screened against the eligibility criteria. Abstracts were then screened and for those identified as relevant or in ambiguous cases, the full text was screened. The final eligibility decision was made by two reviewers (JS \& CS) reading the full text. In three cases, a final agreement was reached with the involvement of third nominated author (MO).

After the full text had been exported, data relating to the sample, design, development, evaluation and feasibility of each outcome measure was extracted onto pre-prepared data extraction forms by two reviewers. The process of this systematic review is outlined in Figure 1. 
Figure 1. Process of the systematic review search

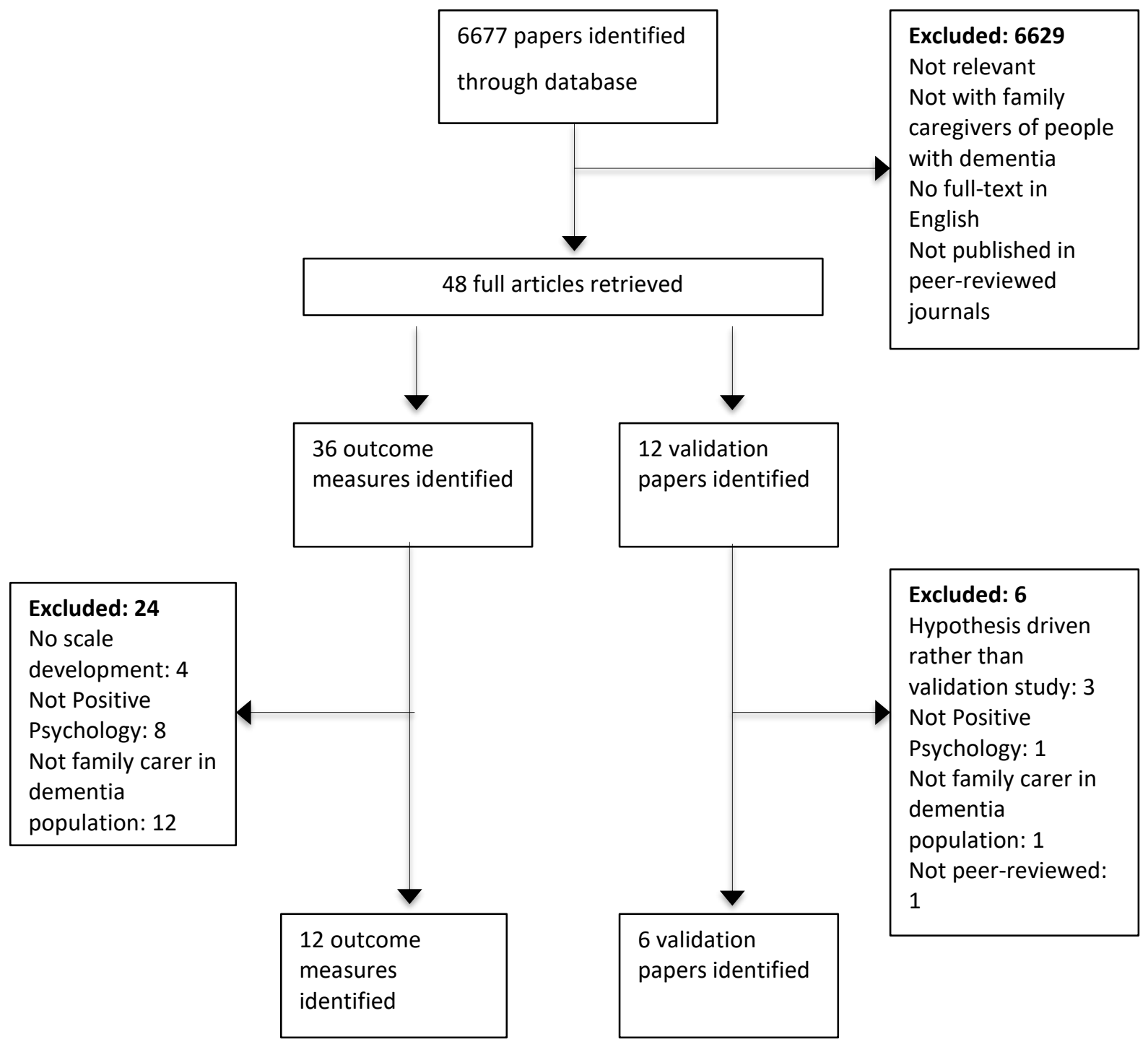

\section{Psychometric Properties}

Identified positive outcome measures were grouped by construct and a quality assessment was conducted using guidance formulated by Terwee et al. (2007) which has been employed in reviews of a similar nature (Windle et al., 2011; Stoner et al., 2015). Two authors (JS \& CS) undertook the quality assessment independently and a consensus meeting was held to discuss any disagreements in the scoring. 
The criterion scores the development of outcome measures based on the reporting of reliability and validity in the development paper. These reported aspects are: a) content validity, b) internal consistency, c) construct validity, d) reproducibility, e) responsiveness, f) floor and ceiling effects and g) interpretability as demonstrated in Table 1. A score of 2 for each criterion was awarded for a study that was well designed and reported. A score of 1 was given if there were methodological flaws in the study design, methods, or if this information was not well reported. A score of 0 was awarded if the study produced poor results despite good methods, or if there was no information found for the given criteria. The individual scores were then added together to assess the overall quality of the development process for the scale with a possible score range of $0-18$, with 18 being the highest available score. For the purposes of this review, the authors have assigned labels to total scores to increase interpretability. Scores 0-4 were assigned a label of 'poor', 5-9 were assigned a label of 'moderate', scores 10-14 were assigned a label of 'good', and scores 1518 were assigned a label of 'very good'.

The appraisal of the scale development papers was conducted to identify scales that had been rigorously developed and well reported, and would therefore be suitable for inclusion in interventional or cross-sectional research. Scores for each individual aspect relating to psychometric properties are presented in Table 2. 
Table 1 quality assessment scoring criteria (adapted from Terwee et al., 2007)

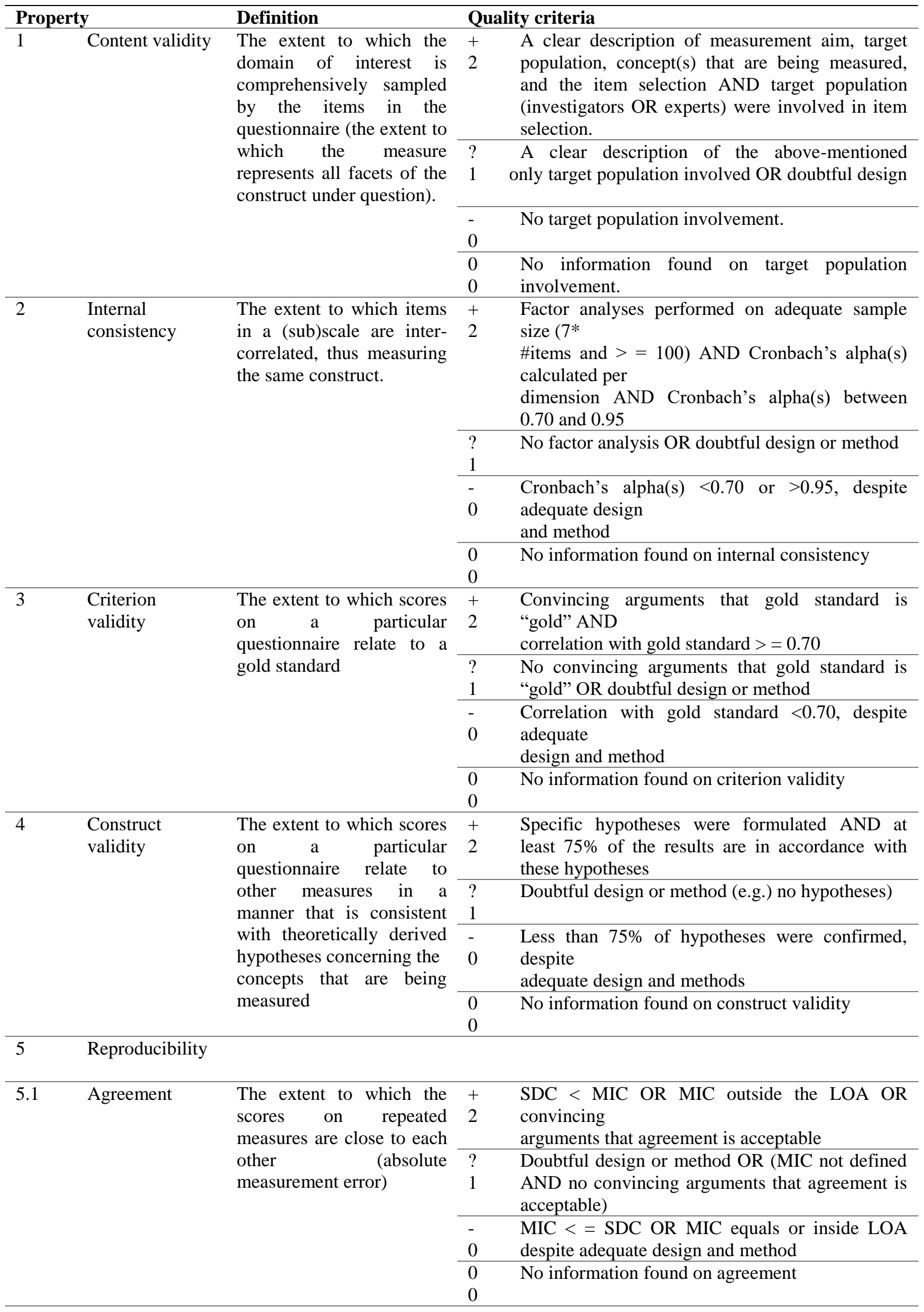




\begin{tabular}{|c|c|c|c|c|}
\hline \multirow[t]{4}{*}{5.2} & \multirow[t]{4}{*}{ Reliability } & \multirow{4}{*}{$\begin{array}{l}\text { The extent to which } \\
\text { patients can be } \\
\text { distinguished from each } \\
\text { other, despite measurement } \\
\text { errors (relative } \\
\text { measurement error) }\end{array}$} & $\begin{array}{l}+ \\
2\end{array}$ & ICC or weighted Kappa $>=0.70$ \\
\hline & & & $\begin{array}{l}? \\
1\end{array}$ & Doubtful design or method \\
\hline & & & $\overline{0}$ & $\begin{array}{l}\text { ICC or weighted Kappa }<0.70 \text {, despite adequate } \\
\text { design and } \\
\text { method }\end{array}$ \\
\hline & & & $\begin{array}{l}0 \\
0\end{array}$ & No information found on reliability \\
\hline \multirow[t]{4}{*}{6} & \multirow[t]{4}{*}{ Responsiveness } & \multirow{4}{*}{$\begin{array}{l}\text { The ability of a } \\
\text { questionnaire to detect } \\
\text { clinically important } \\
\text { changes over time }\end{array}$} & $\begin{array}{l}+ \\
2\end{array}$ & $\begin{array}{l}\text { SDC or SDC }<\text { MIC OR MIC outside the LOA } \\
\text { OR RR }>1.96 \text { OR AUC }>=0.70\end{array}$ \\
\hline & & & $?$ & Doubtful design or method \\
\hline & & & - & $\begin{array}{l}\text { SDC or SDC }>=\text { MIC OR MIC equals or inside } \\
\text { LOA OR RR }<=1.96 \text { or AUC }<0.70 \text {, despite } \\
\text { adequate design and methods }\end{array}$ \\
\hline & & & $\begin{array}{l}0 \\
0\end{array}$ & No information found on responsiveness \\
\hline \multirow[t]{4}{*}{7} & \multirow[t]{4}{*}{$\begin{array}{l}\text { Floor and } \\
\text { ceiling effects }\end{array}$} & \multirow{4}{*}{$\begin{array}{l}\text { The number of respondents } \\
\text { who achieved the lowest or } \\
\text { highest possible score }\end{array}$} & $\begin{array}{l}+ \\
2\end{array}$ & $\begin{array}{l}=<15 \% \text { of the respondents achieved the highest or } \\
\text { lowest possible scores }\end{array}$ \\
\hline & & & $\begin{array}{l}? \\
1\end{array}$ & Doubtful design or method \\
\hline & & & $\overline{0}$ & $\begin{array}{l}>15 \% \text { of the respondents achieved the highest or } \\
\text { lowest possible scores, despite adequate design } \\
\text { and methods }\end{array}$ \\
\hline & & & $\begin{array}{l}0 \\
0\end{array}$ & No information found on interpretation \\
\hline \multirow[t]{3}{*}{8} & \multirow[t]{3}{*}{ Interpretability } & \multirow{3}{*}{$\begin{array}{l}\text { The degree to which one } \\
\text { can assign qualitative } \\
\text { meaning to quantitative } \\
\text { scores }\end{array}$} & $\begin{array}{l}+ \\
2\end{array}$ & $\begin{array}{l}\text { Mean and SD scores presented of at least four } \\
\text { relevant subgroups of patients and MIC defined }\end{array}$ \\
\hline & & & $\begin{array}{l}? \\
1\end{array}$ & $\begin{array}{l}\text { Doubtful design or method OR less than four } \\
\text { subgroups OR no MIC defined }\end{array}$ \\
\hline & & & 0 & No information found on interpretation \\
\hline
\end{tabular}

In order to calculate a total score $+=2 ; ?=1 ;-=0 ; 0=0$ (scale of $0-18$ ). SDC - smallest detectable difference (this is the smallest within person change, above measurement error. A positive rating is given when the SDC or the limits of agreement are smaller than the MIC). MIC - minimal important change (this is the smallest difference in score in the domain of interest which patients perceive as beneficial and would agree to, in the absence of side effects and excessive costs). SEM -standard error of measurement. AUC - area under the curve. RR - responsiveness ratio.

\section{Results}

The initial search identified 6677 papers, of which 48 potential scale development or validation papers were identified through screening abstracts. After screening the full articles, 18 papers met the inclusion criteria. These comprised 12 scale development and 6 validation papers. A scale development paper was defined as a manuscript that describes the process of developing a measure, whereas a validation paper was defined as one that 
tests and describes the psychometric properties of a particular measure, sometimes in a specific population. 
Table 2. Quality criteria scores for the identified outcome measures

\begin{tabular}{llllllll}
\hline Scale & $\begin{array}{l}\text { Content } \\
\text { validity }\end{array}$ & $\begin{array}{l}\text { Internal } \\
\text { Consistency }\end{array}$ & $\begin{array}{l}\text { Criterion } \\
\text { validity }\end{array}$ & $\begin{array}{l}\text { Construct } \\
\text { validity }\end{array}$ & Reproducibility & Responsiveness & $\begin{array}{l}\text { Floor/ Interpretability } \\
\text { ceiling } \\
\text { effects }\end{array}$ \\
& & & & & $\begin{array}{l}\text { Total } \\
\text { score }\end{array}$
\end{tabular}

\section{Agreement Reliability}

\begin{tabular}{|c|c|c|c|c|c|c|c|c|c|c|}
\hline $\begin{array}{l}\text { Revised Scale } \\
\text { for Caregiving } \\
\text { Self-Efficacy } \\
\text { (Steffen et al., } \\
\text { 2002) }\end{array}$ & 2 & 2 & 0 & 2 & 2 & 0 & 0 & 0 & 0 & 8 \\
\hline $\begin{array}{l}\text { Self-Efficacy } \\
\text { Questionnaire } \\
\text { for Chinese } \\
\text { Family } \\
\text { Caregivers } \\
\text { (Zhang et al., } \\
\text { 2012) }\end{array}$ & 2 & 0 & 0 & 0 & 0 & 0 & 0 & 0 & 1 & 3 \\
\hline $\begin{array}{l}\text { Family Carer } \\
\text { Self-Efficacy } \\
\text { for Managing } \\
\text { Dementia } \\
\text { (Fortinsky, } \\
\text { Kercher \& } \\
\text { Burant, 2002) } \\
\end{array}$ & 1 & 2 & 0 & 2 & 0 & 0 & 0 & 0 & 0 & 5 \\
\hline $\begin{array}{l}\text { Sense of } \\
\text { Competence } \\
\text { Questionnaire } \\
\text { (Vernooij- } \\
\text { Dassen, 1993) }\end{array}$ & 2 & 1 & 0 & 2 & 0 & 0 & 0 & 0 & 1 & 6 \\
\hline $\begin{array}{l}\text { Short Sense of } \\
\text { Competence } \\
\text { Questionniare } \\
\text { (Vernooij- } \\
\text { Dassen et al. } \\
\text { 1999) }\end{array}$ & 2 & 2 & 0 & 2 & 0 & 2 & 0 & 0 & 1 & Page 13 of 36 \\
\hline
\end{tabular}




\begin{tabular}{|c|c|c|c|c|c|c|c|c|c|}
\hline Scale & $\begin{array}{l}\text { Content } \\
\text { validity }\end{array}$ & $\begin{array}{l}\text { Internal } \\
\text { Consistency }\end{array}$ & $\begin{array}{l}\text { Criterion } \\
\text { validity }\end{array}$ & $\begin{array}{l}\text { Construct } \\
\text { validity }\end{array}$ & Reproducibility & Responsiveness & $\begin{array}{l}\text { Floor/ } \\
\text { ceiling } \\
\text { effects }\end{array}$ & Interpretability & $\begin{array}{l}\text { Total } \\
\text { score }\end{array}$ \\
\hline
\end{tabular}

Agreement Reliability

\begin{tabular}{|c|c|c|c|c|c|c|c|c|c|c|}
\hline & & & & & & & & & & \\
\hline $\begin{array}{l}\text { Intrinsic } \\
\text { Spirituality } \\
\text { Scale (Hodge, } \\
\text { 2003) }\end{array}$ & 1 & 0 & 0 & 2 & 0 & 0 & 0 & 0 & 0 & 3 \\
\hline $\begin{array}{l}\text { Spiritual } \\
\text { Support Scale } \\
(\mathrm{Ai} \text { et al., } \\
2005)\end{array}$ & 2 & 0 & 0 & 2 & 0 & 0 & 0 & 0 & 0 & 4 \\
\hline $\begin{array}{l}\text { Perceived } \\
\text { Caregiver } \\
\text { Rewards } \\
\text { (Picot et al., } \\
\text { 1997) }\end{array}$ & 2 & 2 & 0 & 2 & 0 & 2 & 0 & 0 & 0 & 8 \\
\hline $\begin{array}{l}\text { Positive } \\
\text { Aspects of } \\
\text { Caregiving } \\
\text { Scale (Tarlow } \\
\text { et al., 2004) }\end{array}$ & 2 & 0 & 0 & 1 & 0 & 0 & 0 & 1 & 1 & 5 \\
\hline $\begin{array}{l}\text { Gain in } \\
\text { Alzheimer } \\
\text { Care } \\
\text { Instrument } \\
\text { (Yap et al., } \\
2010)\end{array}$ & 2 & 2 & 0 & 2 & 0 & 2 & 0 & 2 & 0 & 10 \\
\hline $\begin{array}{l}\text { Finding } \\
\text { Meaning } \\
\text { Through } \\
\text { Caregiving } \\
\text { Scale (Farran } \\
\text { et al., 1999) }\end{array}$ & 2 & 1 & 0 & 2 & 0 & 2 & 0 & 0 & 0 & 7 \\
\hline
\end{tabular}




\begin{tabular}{|c|c|c|c|c|c|c|c|c|c|}
\hline Scale & $\begin{array}{l}\text { Content } \\
\text { validity }\end{array}$ & $\begin{array}{l}\text { Internal } \\
\text { Consistency }\end{array}$ & $\begin{array}{l}\text { Criterion } \\
\text { validity }\end{array}$ & $\begin{array}{l}\text { Construct } \\
\text { validity }\end{array}$ & Reproducibility & Responsiveness & $\begin{array}{l}\text { Floor/ } \\
\text { ceiling } \\
\text { effects }\end{array}$ & Interpretability & $\begin{array}{l}\text { Total } \\
\text { score }\end{array}$ \\
\hline
\end{tabular}

Agreement Reliability

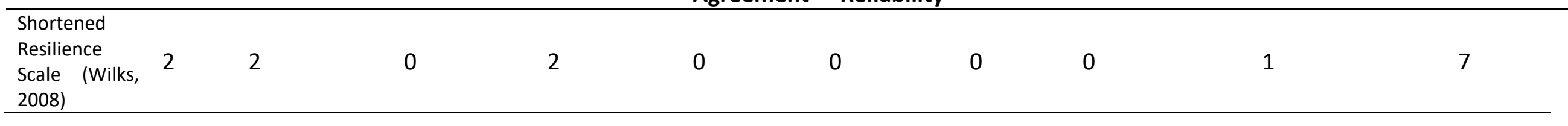

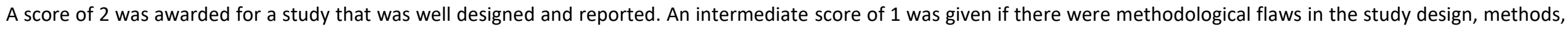

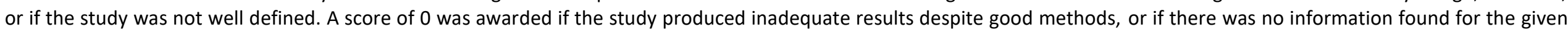

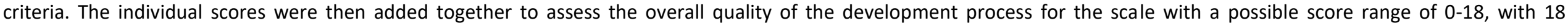
indicating a high quality outcome measure. 
The main reasons for exclusion of papers was that the scales did not measure a positive psychology construct ( 9 excluded), or the population was not family caregivers of people with dementia living in the community (13 excluded).

The outcome measures were grouped by construct to allow ease of comparison across the measures identified and appraised. The scale that scored the highest was the Gain in Alzheimer Care Instrument (GAIN; Yap et al., 2010), which scored 10/18, indicating good validity and reliability.

The constructs identified and number of measures included for each were: Self-efficacy (5), spirituality (2), rewards (3), meaning (1) and resilience (1).

\section{Self-Efficacy}

Five outcome measures were identified for the construct of self-efficacy: The Revised Scale for Caregiving Self-Efficacy (RSSE; Steffen et al., 2002), the Self-Efficacy Questionnaire for Chinese Family Caregivers (Zhang et al., 2012), Family Caregivers' Self-Efficacy for Managing Dementia scale (Fortinsky et al., 2002), the Sense of Competence Questionnaire (SCQ; Vernooij-Dassen, 1993; Vernooij-Dassen et al., 1996), and its short version, the Short Sense of Competence Questionnaire (SSCQ: Vernooij-Dassen et al., 1999).

The RSSE (Steffen et al., 2002) scored moderately in the quality assessment (8/18). However, the development paper for this scale lacked information on responsiveness, floor and ceiling effects, and interpretability. Adequate internal consistency was found for the subscales, ranging from $\alpha=.70$ to $\alpha=.76$. Self-efficacy on the RSSE was found to have strong negative correlations with depression, measured with the Beck Depression Inventory (Beck, Steer and Brown, 1996; $r=.38, p<.01$ ) and with anger on the Spielberg's Trait Anger Scale 
(Spielberger et al., 1983; $r=.45, p<.01$ ). Self-efficacy also had a strong positive correlation with perceived social support $(r=.47, p<.01)$. This indicates that, in line with expectations, higher self-efficacy was linked with lower depression and anger scores, and higher perceived social support scores, indicating good construct validity.

The Chinese Self-Efficacy Scale (Zhang et al., 2012) scored poorly (3/18) on the quality assessment criteria, mainly due to lack of data in reproducibility, responsiveness and interpretability. No reliability and limited validity information was given from the development authors. In a subsequent validation study (Zhang et al., 2013), internal consistency was considered too high $\alpha=0.94$ for the overall scale, which may indicate multicollinearty (overlapping of items). Nevertheless, internal consistency was good for each subscale $(\alpha=0.8)$ and test-retest reliability was good $(\alpha=.74)$.

The Self-Efficacy Scale for Managing Dementia (Fortinsky et al., 2002) scored moderately on the quality assessment criteria (5/18), also due to lack of data in the development paper. This measure demonstrated good internal consistency ( $\alpha=.77$ to .78 ). The subscale of symptom management self-efficacy strongly and positively correlated with sense of competence $(r=.49)$. Higher symptom management self-efficacy scores were associated with fewer dementia symptoms ( $\beta=-.017, p<0.05)$, indicating good construct validity.

The SCQ (Vernooij-Dassen, 1993) scored moderately on the quality assessment criteria (6/18). The SCQ had good internal consistency overall $(\alpha=.79)$ but the subscales did not show good Cronbach's alpha scores, ranging from $\alpha=.5$ to $\alpha=.63$. Good construct validity was found, as sense of competence was negatively correlated with apathy of the person 
with dementia $(r=-.31, p<0.01)$ and duration of dementia was positively associated with the domain of satisfaction with ones own performance as a caregiver $(\beta=-.18, p<.05)$.

The short version of this outcome measure, the SSCQ (Vernooij-Dassen et al., 1999) scored the highest in the construct of self-efficacy (9/18). The SSCQ was developed from the 27item SCQ and was intended for use in clinical practice. There was a good correlation between scores on the SCQ and SSCQ, and the SSCQ was found to have good internal consistency $(\alpha=.76)$.

\section{Spirituality}

Two outcome measures were identified for the construct of spirituality: The Intrinsic Spirituality Scale (ISS; Hodge, 2003) and Spiritual Support Scale (SSS; Ai et al., 2005)

The ISS (Hodge, 2003) was developed using a convenience sample of university students from a Baptist affiliated University. It scored poorly on the quality assessment criteria (3/18). The internal consistency score was found to be too high $(\alpha=.96)$, indicating multicollinearity. Concurrent validity was good, with spirituality negatively correlating with alcohol use, $(r=-.489, p<.001)$ and frequency of binge drinking $(r=-.464, p<.001)$. Spirituality also positively correlated with secure attachment $(r=.223, p=.003)$, indicating good construct validity. A subsequent validation study with caregivers of people with dementia (Gough et al., 2010) found a high Cronbach's alpha $(\alpha=.92)$ and positive correlations with amount of prayer $(r=.50, p<.05)$ and resilience $(r=.44, p<.05)$.

The SSS (Ai et al., 2005) was developed in America with 453 students, 3 months after the September 2001 terrorist attacks. It scored 4/18 in the quality assessment criteria. 
Cronbach's alpha was too high ( $\alpha=.97)$, which was also found in a subsequent psychometric evaluation of the SSS in a sample of Alzheimer's caregivers (Wilks et al., 2013). Spiritual support was found to positively correlate with resilience measured by the Resilience Scale14 (RS-14; $r=.25, p<.01)$, indicating good construct validity.

\section{Rewards}

The Gain in Alzheimer Care Instrument (GAIN; Yap et al., 2010), Positive Aspects of Caregiving Scale (PAC; Tarlow et al., 2004) and Perceived Carer Rewards Scale (Picot et al., 1997) were identified for the construct of rewards.

The GAIN outcome measure and developed for use with caregivers of people with dementia. It scored the highest on the quality assessment criteria of all the scales identified in this review (10/18). The measure demonstrated good internal consistency $(\alpha=.89)$ and test-retest reliability $(\alpha=.79)$. In terms of validity, the authors hypothesised that scores on this measure would negatively correlate with burden, as measured on the Zarit Burden Interview, which was reported in the development paper ( $r=-.01, p=.02)$. Scores on the GAIN measure strongly and positively correlated with scores on the PAC scale $(r=.68, p<.0001)$, which was also developed for caregivers of people with dementia.

The PAC (Tarlow et al., 2004) scored moderately on the quality assessment criteria $(8 / 18)$ and demonstrated good internal consistency $(\alpha=.89)$ and adequate validity. It was positively correlated with wellbeing $(r=.24, p<.05)$, and negatively associated with burden $(r=.23$, $\mathrm{p}<.05)$, though the correlations were weak. A validation of this study for the Chinese version of the measure produced similar results in terms of reliability $(\alpha=.89)$. 
The Perceived Carer Rewards Scale (Picot et al., 1997) was developed with female caregivers of people with dementia. It scored moderately $(5 / 18)$ in the quality assessment criteria. It had good internal consistency $(\alpha=.83)$ and construct validity, as perceived rewards was negatively correlated with caregiver burden $(r=-.35, p<.0001)$, depression $(r=-.30, p<.0001)$ and caregiver demands ( $r=-.22, p=.04)$, as expected. The authors (Picot et al., 1997) recommended further psychometric testing of this measure.

\section{Meaning}

The Finding Meaning Through Caregiving Scale (FMTCS; Farran et al., 1999) was the only outcome measure to be identified for the construct of meaning. This measure had a moderate score $(7 / 18)$ on the quality assessment criteria, mostly due to a lack of information on responsiveness, interpretability and floor and ceiling effects. Internal consistency was high $(\alpha=.91)$ and test-retest reliability was good $(\alpha=.80)$. The 'Provisional Meaning' subscale was positively correlated with marital satisfaction, caregiver satisfaction and personal gain ( $r=.24$ to $.64, p=.01$ ). Divergent validity was supported by the finding of inverse relationships between the loss/powerless subscale and marital satisfaction, caregiver satisfaction and personal gain ( $r=-.38$ to $-.53, p=.01)$.

\section{Resilience}

The only measure identified for resilience that had been developed for or validated with the dementia caregiver population was the Shortened Resilience Scale (Wilks, 2008), which scored moderately (7/18) for scale development. It lacked evidence on reproducibility, responsiveness, and floor and ceiling effects. Internal consistency was too high $(\alpha=.96)$ 
suggesting significant overlapping of items. Construct validity was good, with resilience negatively correlating with stress $(r=-.6, p<.01)$. 
Table 3. Description of included outcome measures

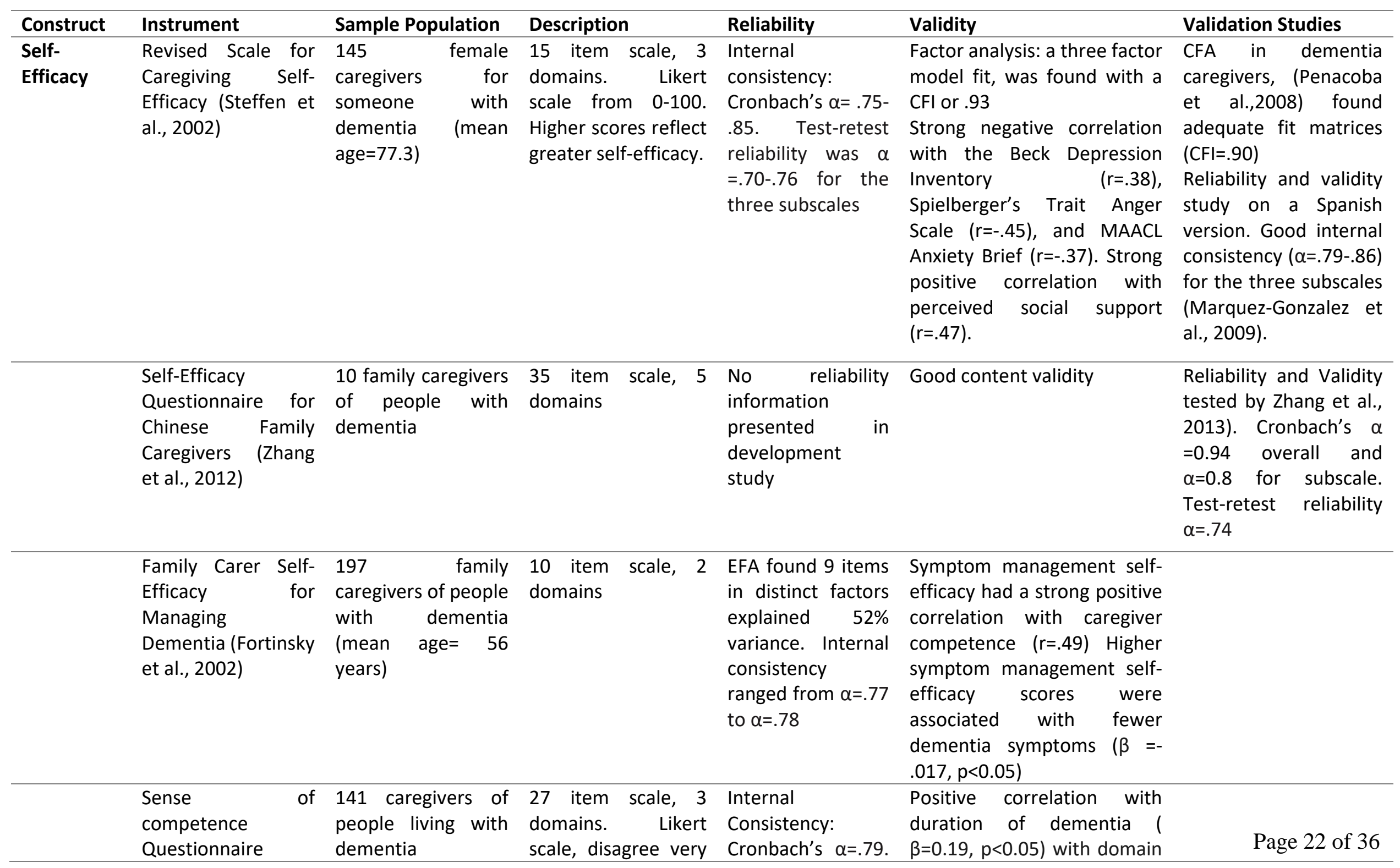




\begin{tabular}{|c|c|c|c|c|c|c|}
\hline & $\begin{array}{l}\text { (SCQ; Vernooij- } \\
\text { Dassen, 1993) }\end{array}$ & & $\begin{array}{l}\text { strongly to agree } \\
\text { very strongly. }\end{array}$ & $\begin{array}{l}\text { Internal } \\
\text { consistency } \\
\text { ranged from } \alpha=.5- \\
69\end{array}$ & $\begin{array}{l}\text { satisfaction with self as } \\
\text { caregiver. }\end{array}$ & \\
\hline & $\begin{array}{l}\text { Short Sense of } \\
\text { competence } \\
\text { questionnaire } \\
\text { (SSCQ; Vernooij- } \\
\text { Dassen et al., 1999) }\end{array}$ & $\begin{array}{l}141 \text { caregivers of } \\
\text { people living with } \\
\text { dementia }\end{array}$ & $\begin{array}{l}7 \text { item scale. Likert } \\
\text { scale, disagree very } \\
\text { strongly to agree } \\
\text { very strongly. }\end{array}$ & $\begin{array}{l}\text { Internal } \\
\text { Consistency: } \\
\text { Cronbach's } \alpha=.76\end{array}$ & $\begin{array}{l}\text { High correlation between } \\
\text { SSCQ and SCQ }(r=.88)\end{array}$ & \\
\hline \multirow[t]{2}{*}{ Spirituality } & $\begin{array}{l}\text { Intrinsic Spirituality } \\
\text { Scale (Hodge, 2003) }\end{array}$ & \begin{tabular}{lr}
\multicolumn{3}{l}{ Convenience } \\
sample of 172 \\
university & students \\
from a & Baptist \\
church affiliated & university. \\
lmean \\
age=19.26). & Two \\
thirds (67\%) & were \\
female.
\end{tabular} & $\begin{array}{l}6 \text { item scale with a } \\
\text { likert scale from } 0 \text { - } \\
10 .\end{array}$ & $\begin{array}{l}\text { Internal } \\
\text { Consistency: } \\
\text { Cronbach's } \alpha=.96\end{array}$ & $\begin{array}{l}\text { Spirituality was negatively } \\
\text { correlated with alcohol use } \\
(r=-.489, p<.001) \text {, frequency } \\
\text { of binge drinking ( } r=-.464 \text {, } \\
p<.001) \text { and positively } \\
\text { correlated with secure } \\
\text { attachment }(r=.223, p=.003)\end{array}$ & $\begin{array}{l}\text { Validation with carers } \\
\text { of people with } \\
\text { Alzheimer's (Gough et } \\
\text { al., 2010). Internal } \\
\text { consistency: } \alpha=.92 \text {. } \\
\text { Validity: Positive } \\
\text { correlation with prayer } \\
\text { frequency ( } r=.50 \text {, } \\
p<.05 \text { ) and resilience } \\
\text { on the Connor-Davis } \\
\text { resilience scale ( } r=.44 \text {, } \\
p<.05)\end{array}$ \\
\hline & $\begin{array}{l}\text { Spiritual Support } \\
\text { Scale (SSS) (Ai, } \\
\text { Peterson \& Huang, } \\
\text { 2005) }\end{array}$ & $\begin{array}{l}453 \text { undergraduate } \\
\text { and postgraduate } \\
\text { students, } 3 \text { months } \\
\text { after the } \\
\text { September } 2001 \\
\text { terrorist attacks. }\end{array}$ & $\begin{array}{l}12 \text { item scale. } \\
\text { Scores between } 1-4, \\
1=\text { Strongly Disagree } \\
\text { and } 4=\text { Strongly } \\
\text { Agree. High scores } \\
\text { reflect greater } \\
\text { spiritual support. }\end{array}$ & $\begin{array}{l}\text { Internal } \\
\text { consistency: } \\
\text { Cronbach's } \alpha=.97 \text {. } \\
\text { EFA showed a } \\
\text { unidimensional } \\
\text { solution, with a } \\
\text { single factor } \\
\text { explaining } 76 \% \text { of } \\
\text { the total variance. }\end{array}$ & $\begin{array}{l}\text { SSS was positively correlated } \\
\text { with frequency of prayer } \\
(r=79, p<.001)\end{array}$ & $\begin{array}{l}\text { Validation of SSS in } \\
\text { Alzheimer's caregivers } \\
\text { (Wilks et al., 2013). } \\
\text { Internal consistency: } \\
\text { Cronbach's } \alpha=.97 \\
\text { Validity: SSS negatively } \\
\text { correlated with } \\
\text { emotion focused } \\
\text { coping ( } r=-.12, p<.01) \text {. } \\
\text { SSS positively } \\
\text { correlated reasured on } \\
\text { resilience meanch }\end{array}$ \\
\hline
\end{tabular}




\begin{tabular}{|c|c|c|c|c|c|c|}
\hline Rewards & $\begin{array}{l}\text { Perceived Caregiver } \\
\text { Rewards (Picot et } \\
\text { al., 1997) }\end{array}$ & $\begin{array}{l}83 \text { female } \\
\text { caregivers of people } \\
\text { with dementia } \\
\text { (mean age=58.9) }\end{array}$ & $\begin{array}{l}27 \text { item measure. } \\
0=\text { not at all, } 1=a \\
\text { little, 2=somewhat, } \\
3=\text { quite a lot, } 4=a \\
\text { great deal }\end{array}$ & $\begin{array}{l}\text { Internal } \\
\text { consistency: } \\
\text { Cronbach's } \alpha=.83 \text {. }\end{array}$ & $\begin{array}{l}\text { Positively associated with } \\
\text { caregiver demands }(r=22 \text {, } \\
p=.04) \text {, and with palliative } \\
\text { coping }(r=.26, p=.02) \text {. }\end{array}$ & \\
\hline & $\begin{array}{l}\text { Positive Aspects of } \\
\text { Caregiving Scale } \\
\text { (Tarlow et al., 2004) }\end{array}$ & $\begin{array}{l}1229 \text { family } \\
\text { caregivers of a } \\
\text { person with } \\
\text { Alzheimer's disease } \\
\text { (mean age= 63) }\end{array}$ & $\begin{array}{l}9 \text { item measure with } \\
2 \text { subscales, self- } \\
\text { affirmation and } \\
\text { outlook on life. } 5 \\
\text { point likert scale } \\
\text { from 1-5, 1= } \\
\text { disagree a lot and } 5= \\
\text { agree a lot. }\end{array}$ & $\begin{array}{l}\text { Internal } \\
\text { consistency: } \\
\text { Cronbach's } \alpha=.89 \\
\text { EFA found two } \\
\text { components with } \\
\text { variable loadings } \\
>.45 \text {. }\end{array}$ & $\begin{array}{l}\text { Positively associated with } \\
\text { wellbeing }(r=.24 p<.05) \text {, self- } \\
\text { reported health ( } r=.01 \text {, } \\
p<.05) \text {, and satisfaction with } \\
\text { received social support } \\
(r=.15 \text {, p<.05). Negatively } \\
\text { correlated with burden ( } r=- \\
.23, p<.05)\end{array}$ & 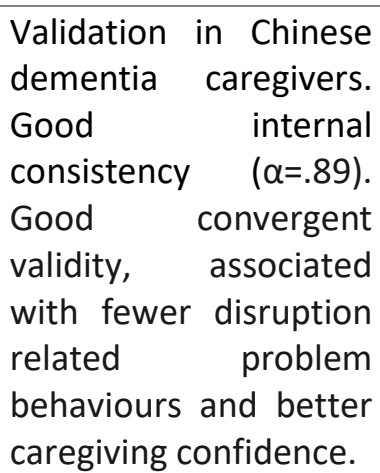 \\
\hline & $\begin{array}{l}\text { Gain in Alzheimer } \\
\text { Care Instrument } \\
\text { (Yap et al., 2010) }\end{array}$ & $\begin{array}{l}321 \quad \text { family } \\
\text { caregivers of people } \\
\text { with dementia } \\
\text { (mean age= } 50.1 \text { ) }\end{array}$ & $\begin{array}{l}10 \text { items. } 5 \\
\text { Responses ranging } \\
\text { from disagree a lot } \\
\text { to agree a lot. } \\
\text { Higher } \quad \text { scores } \\
\text { indicate greater } \\
\text { gain. }\end{array}$ & $\begin{array}{l}\text { Internal } \\
\text { consistency: } \\
\text { Cronbach's } \alpha=.89 \text {. } \\
2 \text { week test-retest } \\
\text { reliability: } \alpha=.79\end{array}$ & $\begin{array}{l}\text { Strongly associated with } \\
\text { scores on the positive } \\
\text { aspects of caregiving scale } \\
(r=.68, p<.0001) \text {, There was a } \\
\text { weak but negative } \\
\text { correlation with burden } \\
\text { measured on the } \mathrm{ZBI}(r=-.01 \text {, } \\
p=.02 \text { ) }\end{array}$ & \\
\hline Meaning & $\begin{array}{lr}\text { Finding } & \text { Meaning } \\
\text { Through } & \text { Caregiving } \\
\text { Scale } \quad \text { (FMTCS) } \\
\text { (Farran et al., 1999) }\end{array}$ & $\begin{array}{l}46 \quad \text { dementia } \\
\text { caregivers } \quad \text { (mean } \\
\text { age=65.53 years). }\end{array}$ & $\begin{array}{l}43 \text { items, 5-point } \\
\text { likert scale. } \\
\text { 1=strongly disagree } \\
\text { to 5=strongly agree. } \\
\text { A higher score } \\
\text { indices greater } \\
\text { meaning. }\end{array}$ & $\begin{array}{l}\text { Internal } \\
\text { consistency: } \\
\text { Cronbach's } \alpha=.91 \text {. } \\
\text { Test-retest } \\
\text { reliability } \alpha=.80 \\
\text { CFA found support } \\
\text { for three } \\
\text { subscales with a } \\
\text { goodness of fit } \\
\text { index of .76, }\end{array}$ & $\begin{array}{l}\text { Provisional meaning subscale } \\
\text { was positively correlated } \\
\text { with caregiver satisfaction, } \\
\text { and personal gain ( } r=.24 \text { to } \\
.64, p=.01 \text { ) }\end{array}$ & \\
\hline
\end{tabular}


$x 2=1444, d f=832$.

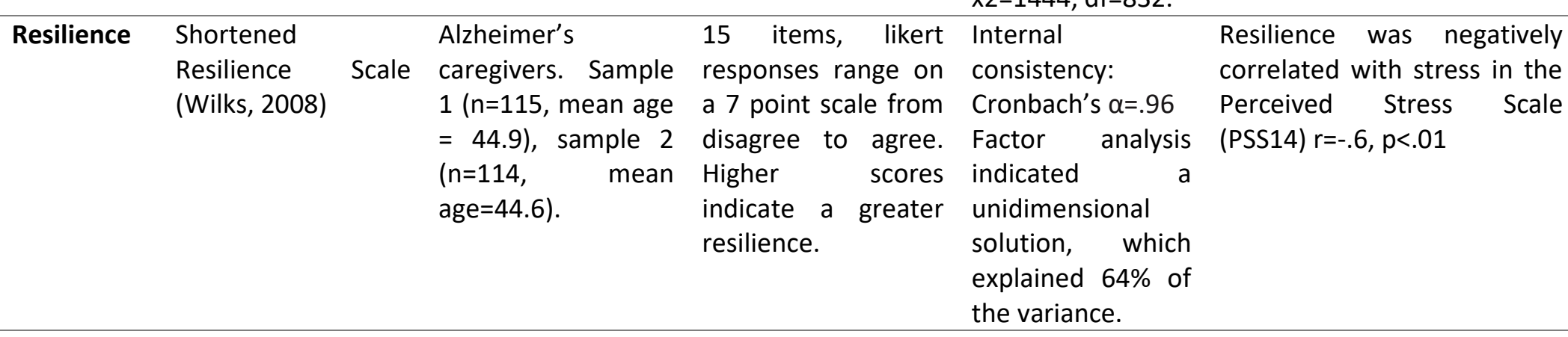




\section{Discussion}

This review is the first to systematically identify and evaluate positive psychology outcome measures for family caregivers of people with dementia, using clear and comprehensive criteria. Twelve outcome measures were identified that had been developed for or validated with this population for the constructs of self-efficacy, resilience, rewards, meaning and spirituality. The majority of scales scored poorly to moderately on the quality criteria, with a lack of information on reproducibility, floor and ceiling effects and responsiveness for most scales. Despite this, the majority of scales reported information for content validity, which would be considered the most important aspect of reporting during development of a measure. Investigators wishing to employ a positive psychology measure with this population may chose a measure based on its underlying theory and relevance to the study rather than total quality score.

Despite the rising recognition of the importance of positive psychology in measuring and understanding wellbeing (Keyes and Lopez, 2005), there are currently a small number of high quality positive psychology scales for these family caregivers. This may be due to the concepts underlying the development of current measures, which are often aligned to the stress-coping model to explain and understand the caregiving experience (Tarlow et al., 2004; Lawton et al., 1991; Pearlin et al., 1990). Whilst there is a comprehensive understanding of how positive aspects of caring can act as protective factors against burden and stress, there is still scope for the development of new measures that draw on models which are more closely aligned to the discipline of positive psychology (Clarke \& Wolverson, 
2016). It is clear that there is an urgent need to develop a theoretical framework that applies positive psychology to dementia caregiving research.

\section{Methodological limitations}

Seligman's definition of positive psychology was chosen due to its inclusive and accessible nature, however, there are a number of alternative theories of positive psychology that may not have been captured in this review, such as Ryff's (1989) scales of psychological wellbeing. Therefore, there is the potential that some scales may have been missed, despite a thorough review process including hand searching of references and prior citations.

Although the scales included in this review relate to concepts that reflect positive psychology literature, an in-depth review of the items in each measure revealed a majority of negative wording in the self-efficacy scales in particular, e.g. in the RSSE, "how confident are you that you can control thinking about unpleasant aspects of taking care of [person with dementia]?" This created ambiguity over whether these measures are truly positive psychology in nature and if they really measure a positive construct. Although these scales were included due to the importance of self-efficacy as a stress-adaption mechanism, it is recommended that negative phrasing should be used in combination with positive wording in order to give a balanced perspective that reflects the co-existence of both positive and negative emotions as indicators of wellbeing. This in turn would more comprehensively represent the co-valence and interplay of positive and negative experiences in caregiving (Clarke \& Wolverson, 2016) 


\section{Future Research}

The quality criteria to assess the development process of the identified scales were used in a related review of positive psychology measures in chronic illness, traumatic brain injury and older adults (Stoner et al., 2015). In both reviews, and an additional previous review of resilience scales (Windle et al., 2011), conclusions were limited due to the under reporting of many of the criteria such as responsiveness and reproducibility. In order to conduct a comprehensive assessment of the quality of a measure, we hope that future authors will report this information in more detail.

This review did not extend to extrinsic factors that may influence wellbeing and only searched for intrinsic positive psychology factors, in order to contain the breadth of the review. Therefore, future authors may wish to conduct a review on positive psychology outcome measures related to extrinsic factors such as

social support and external locus of control to explore how far these aspects contribute to wellbeing.

It is recognised that some of the measures discussed in this review have already been used within interventional research in this population e.g. the SCQ, SSCQ, RSSE and PAC, with variable results. Whilst it is beyond the scope of this review to examine this, future researchers may wish to review the results of such studies from a psychometric viewpoint in order to further assess validity.

There were positive psychology scales frequently in use with family caregivers of people with dementia that were not able to be included in this review because they were 
developed for the general population and have not been validated for family caregivers of people with dementia. Using measures that were developed for a different population and assuming the content validity remains the same is potentially problematic and may limit the conclusions that can be drawn from the studies. Therefore, future authors may wish to conduct in depth psychometric analyses of scales frequently used with family caregivers of people with dementia that have not yet been validated with this population. Such scales include, but are not limited to: the Sense of Coherence scale (Antonovsky, 1993) and the Connor-Davidson Resilience Scale (Connor and Davidson, 2003).

\section{Conclusion}

This review shows that there are some robust measures in existence for family caregivers of people with dementia. These should be incorporated into interventional studies. The most psychometrically sound measure in this review was the GAIN instrument (Yap et al., 2010). It is recommended that this scale be evaluated in an interventional setting, as the development authors were not able to provide evidence of responsiveness.

Although 12 positive outcome measures for family caregivers of people with dementia were identified in this review, there is still work to be done to develop more high quality positive psychology scales for this population. The self-efficacy scales identified within this review contained negative wording and therefore the development of a more positive psychology centered, domain-specific self-efficacy scale is warranted. Development of these scales with a firm theoretical grounding would facilitate a better understanding of the positive aspects of caring and how these contribute to wellbeing. This would ultimately aid in the development of relevant positive psychology interventions. 


\section{References}

Ai, A. L., Tice, T. N., Peterson, C., and Huang, B. (2005). Prayers, spiritual support, and positive attitudes in coping with the September 11 national crisis. Journal of Personality, 73, 763-792.

Alzheimer's Society. (2014). Dementia 2014: Opportunity for change. London: Alzheimer's Society.

Aneshensel, C. S., Pearlin, L. I., Mullan, J. T., Zarit, S. H., and Whitlatch, C. J. (1995). Profiles in caregiving: The unexpected career. London: Academic Press.

Antonovsky, A. (1993). The structure and properties of the sense of coherence scale. Social science \& medicine, 36, 725-733.

Beck, A. T., Steer, R. A., and Brown, G. K. (1996). Beck depression inventory-II. San Antonio: The Psychological Corporation.

Carbonneau, H., Caron, C. and Desrosiers, J. (2010). Development of a conceptual framework of positive aspects of caregiving in dementia. Dementia, 9, 327-353.

Clarke, C., and Wolverson, E. (2016). Positive Psychology Approaches to Dementia. London: Jessica Kingsley Publishers 
Connor, K. M., and Davidson, J. R. (2003). Development of a new resilience scale: The Connor-Davidson resilience scale (CD-RISC). Depression and anxiety, 18, 76-82.

Cooper, C., Balamurali, T. B. S., Selwood, A., and Livingston, G. (2007). A systematic review of intervention studies about anxiety in carers of people with dementia. International Journal of Geriatric Psychiatry, 22, 181-188.

Crellin, N. E., Orrell, M., McDermott, O., and Charlesworth, G. (2014). Self-efficacy and health-related quality of life in family carers of people with dementia: a systematic review. Aging \& mental health, 18, 954-969.

Crespo, M., Lopez, J., and Zarit, S. H. (2005). Depression and anxiety in primary carers: a comparative study of carers of demented and nondemented older persons. International Journal of Geriatric Psychiatry, 20, 591-592.

Dickinson, C., Dow, J., Gibson, G., Hayes, L., Robalino, S. and Robinson, L. (2016). Psychosocial intervention for carers of people with dementia: What components are most effective and when? A systematic review of systematic reviews. International Psychogeriatrics, 26, 1-13.

Farran, C. J., Miller, B. H., Kaufman, J. E., Donner, E., and Fogg, L. (1999). Finding meaning through caregiving: Development of an instrument for family caregivers of persons with Alzheimer's disease. Journal of clinical psychology, 55, 1107-1125. 
Fortinsky, R. H., Kercher, K., and Burant, C. J. (2002). Measurement and correlates of family caregiver self-efficacy for managing dementia. Aging \& mental health, 6, 153-160.

Hodge, D. R. (2003). The intrinsic spirituality scale: A new six-item instrument for assessing the salience of spirituality as a motivational construct. Journal of Social Service Research, 30, 41-61.

Keyes, C. L. M., and Lopez, S. J. (2005). Toward a science of mental health: Positive directions in diagnosis and interventions. In C. R. Snyder \& S. J. Lopez (Eds.), Handbook of positive psychology (pp. 45-62). Oxford, England: Oxford University Press.

Koerner, S.S., Kenyon, D.B. and Shirai, Y. (2009). Caregiving for elder relatives: Which caregivers experience personal benefits/gains? Archives of Gerontology and Geriatrics, 48, 238-245.

Lawton, M. P., Moss, M., Kleban, M. H., Glicksman, A., and Rovine, M. (1991). A two-factor model of caregiving appraisal and psychological well-being. Journal of Gerontology, 46, 181189.

Lazarus, R. S., and Folkman, S. (1984). Stress, appraisal, and coping. New York: Springer publishing company.

Macaskill, A. (2016). Review of Positive Psychology Applications in Clinical Medical Populations. Healthcare, 4, 66. 
Moher, D., Liberati, A., Tetzlaff, J., and Altman, D. G. (2009). Preferred reporting item carers: a comparative study of carers of demented and nondemented older persons. International Journal of Geriatric Psychiatry, 20, 591-592.

Orgeta, V. and Leung, P. (2015). Personality and dementia caring: a review and commentary. Current opinion in psychiatry, 28, 57-65.

Pearlin, L. I., Mullan, J. T., Semple, S. J., and Skaff, M. M. (1990). Caregiving and the stress process: An overview of concepts and their measures. The gerontologist, 30, 583-594.

Picot, S. J., Youngblut, J., and Zeller, R. (1997). Development and testing of a measure of perceived caregiver rewards in adults. Journal of Nursing Measurement, 5, 33-52.

Roff, L. L., Burgio, L. D., Gitlin, L., Nichols, L., Chaplin, W., and Hardin, J. M. (2004). Positive aspects of Alzheimer's caregiving: The role of race. The Journals of Gerontology Series B: Psychological Sciences and Social Sciences, 59 ,185-190.

Ryff, C. D. (1989). Happiness is everything, or is it? Explorations on the meaning of psychological well-being. Journal of personality and social psychology, 57, 1069-1081.

Peterson, C., and Seligman, M. E. P. (2003) Values in Action (VIA) classification of strengths manual. Retrieved from http://citeseerx.ist.psu.edu/viewdoc/download?doi=10.1.1.485.384\&rep=rep1\&type=pdf 
Seligman, M. E., Steen, T. A., Park, N., and Peterson, C. (2005). Positive psychology progress: empirical validation of interventions. American psychologist, 60, 410-421.

Spielberger, C. D., Jacobs, G., Russell, S., and Crane, R. S. (1983). Assessment of anger: The state-trait anger scale. Advances in personality assessment, 2, 159-187.

Steffen, A. M., McKibbin, C., Zeiss, A. M., Gallagher-Thompson, D., and Bandura, A. (2002). The revised scale for caregiving self-efficacy reliability and validity studies. The Journals of Gerontology Series B: Psychological sciences and social sciences, 57, 74-86.

Stoner, C. R., Orrell, M., and Spector, A. (2015). Review of positive psychology outcome measures for chronic illness, traumatic brain injury and older adults: adaptability in dementia? Dementia and geriatric cognitive disorders, 40, 340-357.

Tarlow, B. J., Wisniewski, S. R., Belle, S. H., Rubert, M., Ory, M. G., and GallagherThompson, D. (2004). Positive Aspects of Caregiving Contributions of the REACH Project to the development of new measures for Alzheimer's caregiving. Research on aging, 26, 429453.

Terwee, C. B., Bot, S. D., de Boer, M. R., van der Windt, D. A., Knol, D. L., Dekker, J., Bouter, L. M., and de Vet, H. C. (2007). Quality criteria were proposed for measurement properties of health status questionnaires. Journal of clinical epidemiology, 60, 34-42. 
Tremont, G. (2011). Family caregiving in dementia. Medicine and Health, Rhode Island, 94, 36-48.

Vernooij-Dassen, M. J. F. J. (1993). Dementia and Homecare: Determinants of the Sense of Competence of Primary Caregivers and the Effect of Professionally Guided Caregiver Support. Lisse: Swets \& Zeitlinger

Vernooij-Dassen, M. J., Persoon, J. M., and Felling, A. J. (1996). Predictors of sense of competence in caregivers of demented persons. Social science \& medicine, 43, 41-49.

Vernooij-Dassen, M.J., Felling, A.J., Brummelkamp, E., Dauzenberg, M.G., Bos, G.A. and Grol, R. (1999). Assessment of caregiver's competence in dealing with the burden of caregiving for a dementia patient: a Short Sense of Competence Questionnaire (SSCQ) suitable for clinical practice. Journal of the American Geriatrics Society, 47, 256-257.

Wilks, S. E. (2008). Psychometric evaluation of the shortened resilience scale among Alzheimer's caregivers. American journal of Alzheimer's disease and other dementias, 23, 143-149.

Wilks, S. E., Little, K. G., Gough, H. R., and Spurlock, W. J. (2011). Alzheimer's aggression: Influences on caregiver coping and resilience. Journal of Gerontological Social Work, 54, 260-275.

Wilks, S.E., Ketchum, M. M., Chen, Z., and Bowman, A. M. (2013). Psychometric 
reevaluation of the Spiritual Support Scale in a Sample of Alzheimer's Caregivers. Journal of Religion \& Spirituality in Social Work: Social Thought, 32, 313-329.

Windle, G., Bennett, K. M., and Noyes, J. (2011). A methodological review of resilience measurement scales. Health and quality of life outcomes, 9, 8.

World Health Organization. (2012). Dementia: a public health priority. World Health Organization.

Yap, P., Luo, N., Ng, W. Y., Chionh, H. L., Lim, J., and Goh, J. (2010). Gain in Alzheimer care instrument-a new scale to measure caregiving gains in dementia. The American Journal of Geriatric Psychiatry, 18, 68-76.

Zhang, S. Y., Edwards, H., Yates, P., Ruth, E., and Guo, Q. (2013). Preliminary reliability and validity testing of a Self-Efficacy Questionnaire for Chinese Family Caregivers. Aging \& Mental Health, 5, 630-637.

Zhang, S. Y., Edwards, H., Yates, P., Ruth, E., and Guo, Q. H. (2012). Development of SelfEfficacy Questionnaire for Chinese Family Caregivers. International journal of mental health nursing, 21, 358-365. 